\title{
FORMULACIÓN PSICODINÁMICA DE CASO EN NIÑOS
}

\author{
PSYCHODYNAMIC CASE FORMULATION FOR CHILDREN \\ Delfina Miller
}

\author{
Departamento de Psicología Clínica y de la Salud, Universidad Católica del Uruguay
}

\begin{abstract}
Resumen: La Formulación psicodinámica y dimensional de caso en niños resultará de capital importancia en función de la dificultad que se nos presenta con frecuencia de hacer diagnósticos categoriales en el período de la vida más caracterizado por los cambios. Para hacerla tomaremos especialmente en cuenta el nivel de desarrollo, el entorno en el que crece el niño, su desempeño en diferentes ámbitos y su relacionamiento tanto con pares como con diversos cuidadores. Todos estos aspectos sufrirán cambios permanentes correspondientes al crecimiento del niño y a la lenta adquisición de lo que serán sus rasgos de personalidad que definirán su sentido de sí mismo. Estos elementos, especialmente el acelerado nivel de cambio, generan en muchas ocasiones una dificultad para definir un diagnóstico y más aún para diferenciar lo reactivo, lo intrapsiquico, lo relacional, por lo cual, enfatizando el nivel, las características y condiciones de funcionamiento, consideraremos la formulación clínica como una foto tomada en un momento determinado que nos servirá de referencia para siguientes evaluaciones. Pondremos el énfasis en las herramientas con las que cuenta el niño y en el efecto que el manejo de las mismas podrá tener en el desarrollo.

Detallaremos la forma de sistematizar esta información y ofrecemos a la vez ejemplos y una guía de preguntas que nos orienten en su realización.
\end{abstract}

Palabras Clave: formulación de caso; clínica infantil; diagnostico psicodinámico

\begin{abstract}
The psychodynamic dimensional case formulation for children is crucial in terms of the frequent difficulty to make categorical diagnoses in the period of life characterized by change. To make a clinical formulation of a child we will take particular account of the level of development, the environment in which he/she grows, his/hers performance in different areas and his/hers relationships both with peers and caregivers. All these aspects will suffer permanent changes related to child growth and acquisition of what will be their personality traits that define their sense of self. These elements, especially the rapid rate of change, often generate a difficulty to define a diagnosis and to differentiate it as more reactive, intrapsychic or relational. Emphasizing the level and characteristics and operating conditions we will consider clinical formulation as a photo taken at a certain time that will be useful as a reference for subsequent evaluations. We will put the emphasis on the child tools and on the effect that mental dynamics may have on development.

We will detail how to systematize this information and offer both examples and a guide of questions that can help us in its realization.
\end{abstract}

Key Words: case formulation; children's clinic; psychodynamic diagnosis

\section{Introducción}

A la hora de conceptualizar y presentar los casos clínicos de niños nos vemos muchas veces enfrentados a materiales vagos, poco específicos del caso en cuestión, que recomiendan una intervención psicoterapéutica sin marcar objetivos claros. Esto nos marca claramente la necesidad de una formulación de caso diseñada especialmente para niños y que nos permita identificar que le pasa al paciente, porque le pasa y que podemos hacer para contribuir a un desarrollo saludable.
Los niños se desarrollan y crecen rápidamente, y las características típicas de su desarrollo mental, personalidad, patrón sintomático, y experiencias internas dependen altamente del contexto en el que crecen. Estos dos aspectos, desarrollo y dependencia del contexto, caracterizan la perspectiva desde la cual se debe de formular el caso (Altman, 2014). Comenzaremos entonces por ubicar al niño con respecto a lo esperable para su edad cronológica y evaluaremos el medio en el cual vive y crece, las expectativas y demandas que lo rodean, así como la capacidad de parentalidad de los cuidadores

Correspondencia: Delfina Miller. Departamento de Psicología Clínica y Salud. Facultad de Psicología. Universidad Católica del Uruguay. Correo Electrónico: mmiller@ucu.edu.uy 
para conducir este proceso, tomando estos aspectos como el marco referencial desde el cual estableceremos los criterios diagnósticos y/o de intervención. No debemos de olvidar que el nivel de dependencia del niño de su familia es muy alto y entonces el peso de los modelos, del clima familiar, del lugar que le asignen dentro del grupo será determinante, lo que también incidirá en el vínculo que establezca con el psicólogo y en el lugar que pueda tener en él. Por otro lado el niño incursiona en otros ámbitos (escuela, clubes, etc...) en los cuales le darán y se dará un lugar, lo que incidirá de forma especial tanto en la generación como en el mantenimiento de la sintomatología o en el desarrollo (Dio Bleichmar, 2005).

Tomaremos entonces especialmente en consideración los aportes de diferentes informantes ya que no siempre el niño se comporta igual con todos ellos. Combinaremos esas informaciones y las contrastaremos con la vivencia subjetiva que el mismo nos pueda ofrecer acerca de cómo se siente, que le preocupa, que lo incentiva, lo asusta, etc.

Otro elemento fundamental será el vínculo con pares. Suelo decirles a padres y maestros que el mejor juez de un niño son sus pares. Los niños identifican rápidamente las características más típicas de sus pares y se comportan con ellos de acuerdo a lo que van percibiendo. Esto también incide en la representación de sí que va conformando el niño, la que a su vez condicionará el lugar que ocupe.

Entonces, resumiendo, para hacer una formulación clínica de un niño tomaremos especialmente en cuenta el nivel de desarrollo, el entorno en el que crece, su desempeño en diferentes ámbitos y su relacionamiento tanto con pares como con diversos cuidadores. Todos estos aspectos sufrirán cambios permanentes correspondientes al crecimiento del niño y a la lenta adquisición de lo que serán sus rasgos de personalidad que definirán su sentido de sí mismo. Estos elementos, especialmente el acelerado nivel de cambio, generan en muchas ocasiones una dificultad para definir un diagnóstico y más aún para diferenciar lo reactivo, lo intrapsíquico, lo relacional, por lo cual, enfatizando el nivel y las características y condiciones de funcionamiento, consideraremos la formulación clínica como una foto tomada en un momento determinado y que nos servirá de referencia para siguientes evaluaciones. Pondremos el énfasis en las herramientas con las que cuenta el niño y en el efecto que el manejo de las mismas podrá tener en el desarrollo (Miller, 2013).

Un elemento a destacar es el alto nivel de inferencia que caracteriza las evaluaciones a niños ya que el material que tomamos como base no son solamente los discursos de padres o referentes, o del mismo niño, sino especialmente el juego, las expresiones gráficas, las acciones, o los relatos de situaciones imaginarias. Es a través de estas expresiones que el niño evidencia sus deseos, ansiedades, conflictivas y defensas y se comunica con nosotros ofreciéndose para ser conocido y acompañado.

Estas expresiones, asimiladas por Melanie Klein (1962) a las palabras y sueños de los adultos, se dan en diferentes niveles que van desde la descarga hasta la más alta simbolización y requieren de ser interpretadas en el contexto de historia y entorno del niño. Ellas nos muestran el mundo interno, las herramientas estructurales y la interpretación que hace el niño de la realidad, en ese vaivén permanente entre el principio de placer y el de realidad. Resulta entonces de capital importancia mantener una actitud empática, lúdica, expresiva, que habilite al niño, al mostrarle el valor de esas expresiones así como su relación con lo que él siente, hace, o simplemente le sucede.

Al sentirse espejado y acompañado el niño suele evidenciar muy directamente su sentir y pensar en ese espacio intermedio que se crea entre el psicólogo y el paciente y que al decir de Winnicott (1982) es el lugar no sólo de la comprensión sino especialmente de la reparación, del jugar y fantasear donde se reconstruye la historia y características del niño dando lugar a nuevas alternativas de significación que puedan generar un mejor funcionamiento.

Otro aspecto a destacar es la importancia de determinar el nivel de funcionamiento mental del niño sobre el cual se va a asentar su estructuración. Se nos hace presente en el análisis de los casos por un lado la dificultad de diagnosticar un trastorno ya constituído y por otro la necesidad de identificar rasgos, tendencias y modos de organización que serán sin duda precursores de la organización definitiva.

Es tomando en cuenta la mayor flexibilidad esperable en los niños -que habilita sus posibilidades de cambio-, que nos focalizaremos especialmente en sus herramientas, sus aspectos más sanos y fuertes, así como en 
las posibilidades de comprensión y apoyo del entorno, para apoyar en ellos la intervención.

Pondremos entonces el acento en los aspectos más diferenciales y propios de cada niño (diagnóstico dimensional), para luego contextualizarlos en lo esperado para su edad y condiciones (diagnóstico categorial), buscando comprender el modo en que cada uno experimenta su personalidad, sus trastornos, su forma de ser y estar en el mundo. Consideraremos la sintomatología de origen psíquico como expresión de una falla estructural o de un conflicto y la relacionaremos con el nivel de desarrollo, evaluando los funcionamientos saldables y los más comprometidos, en su expresión consciente o inconsciente. Apuntamos por tanto a una formulación de caso individualizada y amplia a la vez que resulte especialmente útil para planificar la intervención, tomando especialmente en cuenta el acelerado proceso de crecimiento y desarrollo propio de esta etapa de la vida.

Para realizar la evaluación nos basaremos en la historia de desarrollo, haremos una revisión detallada de síntomas (que pueden incluir una evaluación biomédica), exploraremos el contexto familiar, escolar y social y observaremos el comportamiento del niño con nosotros, con sus padres, en el ámbito escolar. Relacionaremos todo esto con la evaluación clínica, que en el caso de los niños estará constituída por entrevistas de juego o semidirigidas, dibujos, relatos, en fin, diversas producciones que no solamente consideren la conducta o el discurso manifiesto del niño sino fundamentalmente la dinámica psíquica que lo sostiene. Nuestras herramientas serán entonces tanto las entrevistas a diferentes informantes, los encuentros con el niño, las entrevistas de juego con él, así como la aplicación de técnicas diagnósticas y estrategias de intervención (Miller, 2013)..

Podremos organizar la información de acuerdo a la propuesta del PDM (Psychodynamic Diagnostic Manual, 2006) comenzando por una mirada microscópica sobre las funciones mentales del niño, su manera de experimentar relaciones y emociones y especialmente como se enfrenta a la ansiedad (Eje M), luego se evalúa la forma como el niño se organiza de acuerdo a sus características y condiciones, o sea que se evalúan los patrones de funcionamiento de su personalidad y su organización (Eje P). Finalmente, se caracterizan los síntomas del niño dentro de esa organización de personalidad y se evalúa su gravedad, es decir si constituyen un trastorno (Eje S). Se evalúa la gravedad del sufrimiento mental y emocional del paciente, el patrón sintomático de cada persona, en relación a otros que tienen cualidades similares, dando especial atención a la forma como el paciente vive y maneja su enfermedad. Pondremos entonces el énfasis en conocer la personalidad y no sólo en la enfermedad, evaluando la severidad del trastorno en términos de su funcionamiento mental, pensando en términos de desarrollo, crecimiento, bienestar y calidad de vida.

De esta manera precisaremos el diagnóstico, lo cual nos permitirá definir la indicación (psicoeducación, seguimiento, psicoterapia, derivación) y planificar la intervención (individual o familiar, con la intervención de uno o más especialistas) en aras de una mayor efectividad.

Una Formulación Psicodinámica de Caso de Niños (FPCN) incluirá entonces la consideración de los siguientes aspectos, expresados de forma breve (500 palabras), concisa y conceptual de forma de poder ser incluída en la historia clínica y orientar con respecto al diagnóstico, pronóstico y evolución del paciente en cuestión.

\section{Diagnóstico}

1. A quien (datos filiatorios sobresalientes, nivel de desarrollo, aspectos significativos del entorno).

2. Le está pasando qué (motivo de consulta), cómo lo vive el mismo (vivencia subjetiva de la enfermedad), cómo lo vive el entorno (familia, institución educativa, otros significativos).

3. Con qué diagnósticos (a nivel biológico, psicológico y social).

4. Con qué nivel de funcionamiento mental e interpersonal (comparar nivel de funcionamiento esperado con nivel adquirido, diferenciando las herramientas con las que cuenta el niño y la incidencia que tenga la conflictiva intrapsíquica y/o externa).

\section{Etiopatogenia:}

1. Con qué historia personal y familiar (factores predisponentes).

2. En qué momento y circunstancias de su vida (factores desencadenantes).

Tratamiento (Plan Terapéutico):

1. Qué abordaje(s) terapéutico(s) (sucesivos o combinados, individuales o familiares).

2. Para atender qué focos (reformulación del 
motivo de consulta de los padres y del niño para acceder a una demanda que pueda ser satisfecha).

3. Con qué resultados esperables (alianza terapéutica, fortalezas y vulnerabilidades para el cambio relacionadas al nivel de desrrollo y a las herramientas adquiridas o en adquisición).

\section{Evolución y Pronóstico:}

1. Aspectos en los cuales hubo cambios positivos, negativos o sin cambio (tomando en consideración los diferentes ámbitos en los que se desempeña el niño, prestaremos atención tanto a los cambios comportamentales como a los intrapsíquicos y diferenciaremos los que son propios del crecimiento y los que consideramos producto de la intervención.

2. Otros tratamientos recibidos o indicados

3. Pronóstico e incidencia en el desarrollo

En el documento anexo se encuentran las preguntas- guía que resultarán de utilidad para la elaboración de la formulación.

\section{Presentación de casos}

Para dar muestra de la utilidad de este tipo de formulación presentaremos dos casos, que luego compararemos, con el objetivo de definir las estrategias con mayor especificidad y efectividad.

\section{CASO 1}

Delmira tiene 8 años 6 meses, procede de un medio socioeconómico deficitario. Está cursando 2 año en Escuela Pública habiendo repetido primer año por inasistencias.

\section{Núcleo familiar:}

La niña es concebida en un encuentro casual de la madre con un vecino del barrio para quien ella trabajaba como empleada doméstica.

Madre, de 27 años, nivel de escolaridad primaria completa, actualmente no trabaja y vive de changas o de diferentes parejas con las que convive ocasionalmente. Se encuentra en este momento en tratamiento psiquiátrico ya que padece un retardo mental moderado, trastorno bipolar, trastorno de personalidad limítrofe.

En este momento convive con un hombre 15 años mayor que ella, obrero metalúrgico, que es quien hace tres años se hace cargo de la manutención de ambas.

Hermana de 7 años, por línea materna, que cursa primer año en Escuela Pública

El padre de Delmira (alcohólico), de 54 años, obrero de la construcción, convive con su pareja y no mantiene contacto con la niña desde hace 4 años.

Los padres de Delmira se separaron a los dos años de la niña luego de reiterados episodios de violencia intrafamiliar severa (insultos, golpes, heridas). La madre expresa: "era muy chiquita así que no se acuerda de nada, y por lo menos ella nos tenía a nosotros, yo ni eso...yo me crié en el INAU ${ }^{1}$ y después pasé a cuidadora y después rejunté con el Beto (padre de la niña), así que nunca estuve sola"

Luego de la separación que se da por una denuncia de los vecinos alarmados por la violencia, la niña y su madre pasan a vivir en un centro de atención para víctimas de violencia doméstica: "Yo ni loca la dejaba, no me iba a quedar sola, sin ella, y en el centro la pasábamos bien, comíamos y dormíamos juntas y así nos pasábamos todo el día". Viven 3 años en el centro, con varios períodos en los que abandonan el hogar y viven en la calle ("me aburrían con tanta cosa, y se armaban tremendos líos y nos íbamos y después volvíamos cuando teníamos hambre") o con alguna pareja de la madre "siempre aparecía alguien con quien estar").

Durante estos años Delmira mantiene contacto esporádico con su padre por iniciativa de su madre que la lleva a visitarlo ("No me podía olvidar de él"). En varias oportunidades la madre le solicita al padre que se haga cargo de la niña o la deja en casa del padre y no regresa por varios días "Hay veces que no la aguanto más, y el es tan padre como yop madre, que la tenga y me la saque un poco de encima"). Cuando el padre se negaba a quedarse con la niña la madre se dirigía a diferentes centros públicos solicitando que se hicieran cargo de la niña a la que abandonaba en esos centros volviendo días más tarde arrepentida y desesperada por ver a la niña y llevarla con ella.

Desde los 5 años de edad, Delmira ha sido ingresada en esos centros en múltiples oportunidades por éste motivo, siempre junto a su madre, permaneciendo desde unos días hasta varias semanas, regresando luego al hogar materno. En 2010, ante la reiteración de estas situaciones, se interna a la niña en un hogar de INAU por

${ }^{1}$ INAU (Instituto del Niño y el Adolescente del Uruguay) 
orden judicial. Su madre la visitaba regularmente todas las semanas. A los seis meses a pedido de ambas es entregada nuevamente a su madre.

\section{Motivo de Consulta:}

Crisis de excitación psicomotriz

\section{Enfermedad Actual:}

Es llevada por su madre a un servicio de emergencia luego del episodio de excitación psicomotriz con heteroagresividad. La madre no logra precisar un desencadenante "estábamos hablando y nos peleamos y ella no sabe discutir, se pone así". Refiere que Delmira se enoja y comienza a tirar y romper objetos de la casa, patea puertas y muebles y al intentar calmarla le pega "cachetadas y patadas". El episodio comienza a ceder al decirle que la traerán al hospital para dejarla. En la emergencia la niña se presenta tranquila y refiere que no recuerda lo que sucedió "es siempre mi mamá la que empieza, yo estoy quieta y ella empieza, yo no la entiendo". La madre refiere episodios similares desde etapas tempranas del desarrollo de Delmira.

La describe como una bebé difícil, "imposible de conformar desde que nació", irritable, inquieta, con dificultades en el sueño (insomnio de conciliación, despertares nocturnos frecuentes, pesadillas y terrores nocturnos) y la alimentación (sumamente selectiva oscila entre comer desmesuradamente a seleccionar exhaustivamente los alimentos).

En la etapa preescolar refiere rabietas frecuentes, de larga duración, con importante descontrol y heteroagresividad dirigida principalmente hacia su madre. "Se tiraba al piso y gritaba y pegaba y si me acercaba me pegaba a mi. Yo me iba afuera de la casa y la dejaba sola, y ya se le iba a pasar".

Sumamente sensible parece estar alerta en todo momento, reaccionando de forma impulsiva frente a cualquier situación inesperada o no deseada.

Tiene miedo a la oscuridad, a la noche, a los animales pequeños, a las escenas violentas.

\section{Pautas de desarrollo:}

Embarazo y parto sin particularidades desde el punto de vista médico. Clima familiar de alta violencia tanto cuando convivía con su opadre como luego con las diferentes parejas de la madre..

Dificultades en el sueño desde el nacimiento ("casi no dormía, estaba siempre despierta, y se movía todo el tiempo, no era lindo tenerla a upa, parecía que se iba a caer de tanto que se sacudía, nada la calmaba, yo la sacaba afuera hasta en invierno y parecía que ese frío la dejaba más quieta y al final se dormía ella o me dormía yo ")

Dificultades en la alimentación: "No quería comer, nunca me tomó la teta, leche de vaca nomás. Me daba una rabia, tenía que gastar plata en vez de darle de comer gratis....eso hasta que nos fuimos al refugio, allí si comía y se hacía amiga de todos, todos la querían y muchas noches ni dormía en mi cama, se me iba a la cama de alguna otra, y dormía. Se ve que de chiquita que la tenía conmigo.....o que se juntaba con cualquiera que le hiciera un mimo... Control de esfínteres: "Y por allí no más se dejó de hacer en los pañales, yo no le podía comprar y además si se hacía no la podía dejar en ningún lado, y ella se dejó, y ya no se hizo más de nada..."

Juegos: "Siempre encontraba con quien jugar, pero los juegos eran a peleas, a los novios, jugaba a la "estufa", que quería decir que si alguien la tocaba ella "quemaba" y entonces se ponía a gritar y pegaba"

Aprendizaje: "Aprende de todo, cuando no se enoja.... las maestras la quieren al principio y ella está en todo, ya sabe leer y escribir mejor que yo. Eso por suerte siempre anda bien. La cosa es como se porta...."

Afectos: "Triste la veo pocas veces, ella está muy contenta o muy enojada, y siempre es conmigo. Con el padre no hace eso, se porta mejor, a mi me abraza y me quiere o me pega..y duele... No es mal humor es rabia."

Normas: "Hacer caso no hace, solamente cuando quiere pedir algo, allí si es una princesita. Y lo mismo pasa en la escuela, ella aprende cuando quiere y si le gusta la maestra, si no salta y corre todo el tiempo, hace lo que le da la gana. Ya le dije que la maestra la va a echar y yo la voy a dejar en el INAU, capaz que me puedo quedar yo también. Si pudiera viviríamos bien, como en el refugio, si nos cuidan, andamos."

Amigos: "¿Amigos? ¿nosotros? ¿de dónde? Estamos de un lado para otro, no tenemos amigos, ella juega y también pelea. Le gusta estar con los más chiquitos, con ellos no es mala, los cuida, y juega a que son sus hijos. Con los más grandes se queda quieta, pero la echan, o si no se hace novios y dice que se va a casar hasta que se pelean y se pegan y se gritan..."

Desde el punto de vista psiquiátrico, en el área conductual presenta exacerbación de sus alteraciones conductuales, en los últimos meses, con crisis de auto y hetero agresividad, de 
intensidad severa, dirigida especialmente a su madre. Rabietas fuertes, de difícil control, frente a mínimas frustraciones. No acepta reglas, no respeta figuras de autoridad. Oposicionista y desafiante.

El personal de las instituciones donde ha estado internada refiere que es una niña muy difícil de manejar. Pasa de ser muy cariñosa y apegada a enojarse y gritar y pegar ferozmente frente a demandas que no se le pueden satisfacer. Varias veces suelen solicitar ayuda para poder contener su agresividad que se vuelve indiscriminada. Estas crisis son notoriamente más intensas y frecuentes cuando su Madre no se presenta y ella llora a gritos y clama por su Mamá. Frente a los intentos de coinsuelo grita, "déjame, vos tenés la culpa, no le decís a mi Mamá donde estoy" Pasados estos episodios dice no recordar nada y no comprender porqué están enojados con ella. También suele preguntar a las personas que la cuidan si no quieren ser su madre. Busca pares con quienes establece vínculos muy dependientes que se quiebran con facilidad y se transforman en fuertes peleas con muy marcada violencia "Me quiere matar!!!! Esto se llena de bichos!!! Yo no le hago nada y me corre, me tengo que divorciar".

Presentación: La niña tiene una apariencia agradable, se presenta vestida acorde a su edad y sexo, evidenciando un nivel de crecimiento adecuado. Sumamente inquieta, se escapa de la sala varias veces. Muy desinhibida "Yo me llamo Delmira, y ¿vos como te llamás, que hacés acá?, ique fea letra que tenés!". Por momentos seductora, manipula para lograr lo que desea. Lenguaje rico, buen caudal lexical. Se infiere muy buen nivel intelectual.

En las entrevistas llora varias veces, expresando que en la escuela no la quieren, que está fea peinada o que el dibujo le sale mal. El llanto es breve y rápidamente pasa a la accción: se escapa, saca todos los juguetes de la caja, se mira al espejo y se peina, siempre sin perder de vista a la entrevistadora.

\section{Primer encuentro}

El primer encuentro se realiza con la niña y su madre. Mientras se entrevista a la madre se le dan a ella hojas y colores. Ella se mueve constantemente e interviene en la conversación, frente a lo cual su madre la amenaza con la mano y ella corre, se escapa o se ríe.

Ante la pregunta de si sabe porqué está allí res- ponde "porque mi mamá me pega, para que no me pegue más" ¿Y por qué te pega? "Porque yo le pego también, no me deja jugar con el Wilson y somos novios y él me quiere, y ella me hace irme para adentro..." Mientras dice todo esto va mirando los materiales que están sobre la mesa y espontáneamente se pone a dibujar:
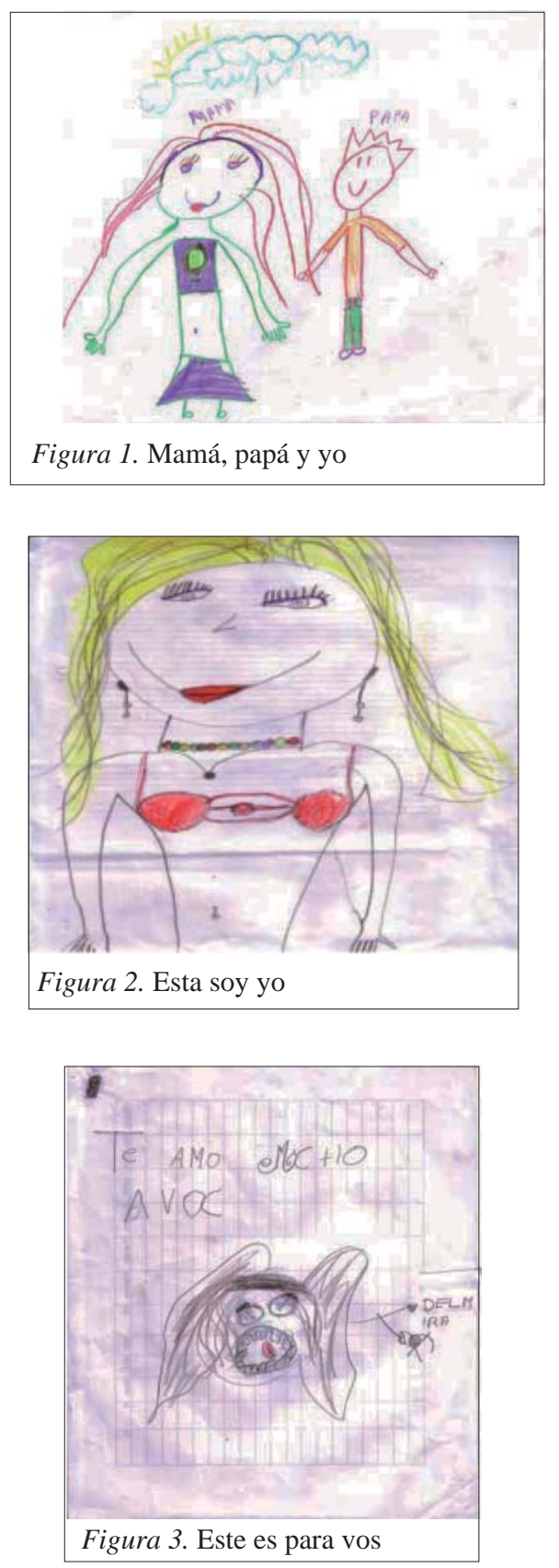

\section{Segundo encuentro}

Se presentan la madre y la niña. La madre entrega un informe de la maestra que evidencia como 
la niña comienza siendo "una niña adorable" $y$ ahora se ha transformado en "insoportable" $y$ la niña trae en la mano el trabajo que acaba de hacer en la escuela. Se hace pasar solamente a la niña. Entra contenta, cantando y le da un fuerte abrazo a la entrevistadora. Se dirige hacia los materiales y se pone a dibujar "No me sale, ique idiota! AAAAAAAAA", grita mientras pasa al otro dibujo "Hoy vinimos temprano, yo no quiero estar en el INAU, ¿Mamá me va a esperar ahora? Sale varias veces durante la entrevista a confirmar si la madre estaba allí. "Yo me enojo y Mamá no me aguanta," ¿Y por qué te enojás tanto? "No sé me viene algo y pateo... Mamá dice que es con ella, no sé" Se pone a llorar. En la escuela no me quieren, me peleo con todos, con la maestra también, no sé...soy así, rabiosa me dicen, La entrevistadora le dice que de pronto ella está muy asustada de que la mamá se vaya y que por eso se enoja tanto. No responde verbalmente y dibuja un "indio tembleque".

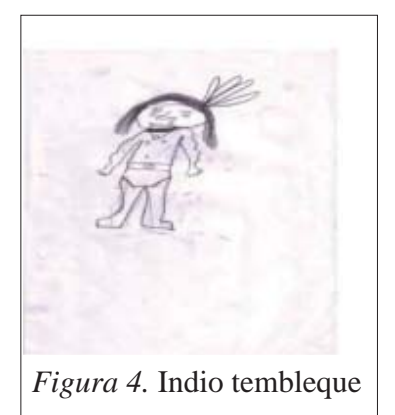

La entrevistadora le sigue hablando de su temor, de su estadía en el INAU y de que ahora está con su mamá y la niña hace el dibujo: "A la casa de Mamá".

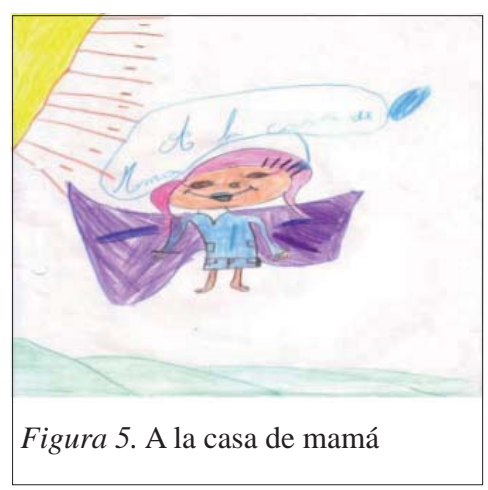

"Yo no quiero que me deje, no quiero pegarle, ni patearla, ni las rabietas" Decile a Mamá y a la maestra, decile que yo puedo. (Dibujo: "Flor Corazón").

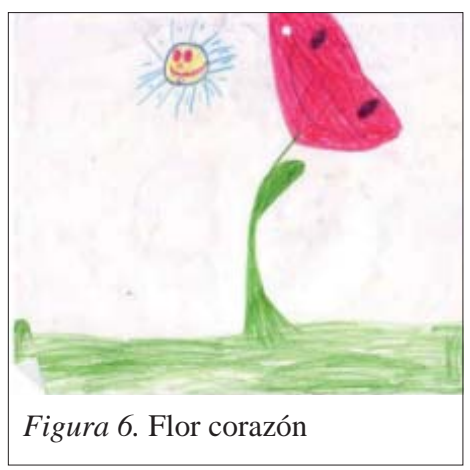

En otro momento le pregunta a la entrevistadora, ¿tu sos doctora? ¿me vas a dar una pastilla para estar mejor? Cuando me dan pastillas, dice Mamá que estoy mejor, y cuando vengo acá también, me gusta dibujar con vos, ¿me vas a ayudar? ¡Te quiero muuuuuchooooooo!!!!! Mientras dibuja canturrea una canción cuya letra es "Loca, loca loca....."

\section{Formulación de caso Delmira}

Delmira, de 8,6 años, vive alternativamente con su madre o en instituciones de cobijo. La inestabilidad y el abandono caracterizan su historia ya que sus padres, luego de una relación muy tormentosa, se separaron siendo ella muy pequeña. Con el padre mantiene un contacto muy esporádico y la madre oscila entre necesitarla como compañía y abandonarla en diferentes instituciones.

Consultan por crisis de angustia y excitación que desbordan no solamente a quienes viven con ella sino también al personal de las instituciones (escuela, hospital, centros de internación) a las que concurre. La niña expresa esta angustia a través de un fuerte pedido de ayuda en el que evidencia la ambivalencia de las representaciones de sí misma que generan vínculos conflictivos y ambivalentes, marcados por fuertes actuaciones. Funciona en un nivel fronterizo en el cual se destaca su vulnerabilidad, su fuerte dependencia del entorno, la inconsistencia de la imagen de sí misma, sus defensas primarias que suponen un intento de integrar y diferenciar un yo que se siente desbordado $y$ en riesgo. A una fuerte conflictiva familiar se agrega una intrapsíquica sostenida por procesos cognitivos primarios atravesados por una desregulación de sus afectos que impide un 
adecuado nivel de procesamiento mental de sus experiencias tanto externas como internas. Los afectos negativos la invaden, generando un estado de alerta permanente teñido de una fuerte ansiedad persecutoria y un sentimiento de desprotección que busca compensar con sus actuaciones. Este funcionamiento afecta su capacidad de aprendizaje dadas las múltiples dificultades en el procesamiento de la información.

Su capacidad de relacionarse con los demás es superficial y orientada a la satisfacción de sus necesidades, lo que resulta en relaciones carentes de intimidad o empatía. En algunas relaciones específicas, puede leer las intenciones de los demás (tales como la aceptación o el rechazo), pero es incapaz de leer señales más sutiles (p.e., respeto, orgullo o enojo parcial). Para poder lidiar tanto con los estresores internos como con los externos, y para poder mantener pensamientos y sentimientos perturbadores fuera de la consciencia, Delmira hace un uso generalizado de aquellas defensas que distorsionan y/o limitan la experiencia de las relaciones sociales. Éstas incluyen la escisión, la negación, la proyección y el actuar impulsivamente (acting out). Utiliza las representaciones o ideas de una forma concreta y actúa sus deseos y sentimientos, lo que provoca la fragmentación o la polarización (los extremos del todo o nada) de la experiencia interna.

Sus capacidades de auto-observación son restringidas. No puede reflexionar genuinamente sobre sus sentimientos o experiencias, aún sobre las actuales. La consciencia que tiene de sí misma generalmente se polariza entre estados emocionales o emociones básicas simples sin una apreciación de las variaciones sutiles de los mismos. No existe una sensibilidad hacia sus propias capacidades y contextos sociales. Experimenta un sentimiento de culpa más como una manifestación de autocrítica que como una señal de la reevaluación de su conducta.

Todo esto nos dice que Delmira evidencia restricciones mayores en su funcionamiento mental, dentro de una personalidad severamente disfuncional, en alto riesgo de configurar un trastorno de personalidad.

Se indica una psicoterapia focalizada en la regulación de sus afectos como forma de mejorar su capacidad de mentalización, a través de la cual se espera un mayor control de sus impulsos, una imagen de sí más consistente e integrada y en consecuencia un relacionamiento más genuino y estable. El trabajo del vínculo transferencial-contratransferencial resultará la base sobre la cual se instaurará el trabajo.

\section{CASO 2}

Presentaré ahora un material de un niño de 6 años y 8 meses a partir del cual quisiera pensar acerca de las cuestiones planteadas anteriormente. Pedro a los 6 años y ocho meses es derivado por la institución escolar a partir de las burlas de que es objeto por parte de sus compañeros a las que él responde con una agresividad descontrolada. Solicita la consulta el padre, y se presenta sólo al primer encuentro, en el que plantea el alivio que sintió cuando desde el colegio se exige una consulta que él venía planteando a la madre, desde hace ya largo tiempo, sin posibilidad de instrumentarla ante la negativa de ella. Es un hombre grande, con aspecto fuerte, en el que destacan sus ojos de mirada fría y cortante.

Los padres están separados desde hace 3 años por infidelidad de la madre con una mujer con quien hoy comparte su vida. Pedro es el único hijo de esta pareja que, al decir del padre, tenía una muy buena relación hasta que el niño nació. Luego de esto la relación se fue deteriorando, las peleas eran muy frecuentes y la madre comienza a retraerse de todas sus actividades (inclusive de su trabajo) para dedicar todo su tiempo al cuidado de este bebé. El padre plantea que esto fue transformando al niño y que eso es lo que hoy determina las burlas de sus compañeros. Está muy enojado con la madre y aclara que no es por su orientación sexual sino por no poder aceptar que el niño necesita que le ayuden a transitar con una orientación sexual que él, el padre, ya tiene claro que es homosexual y que dice aceptar. Agrega que su esposa actual le apoya, por lo cual su pedido es ese: que le ayuden acompañar a su hijo para que pueda sostener su homosexualidad y no le suceda como a la madre que la escondió durante 30 años con todos los "traumas que esto le significó a ella y a mi"..."de esta forma el también va a estar bien con su madre y podrá seguir viviendo con ella... y yo podré armar lo mío más tranquilo".

La madre acude con su pareja y permanecen ambas sentadas juntas durante todo el encuentro, tomándose de la mano en las ocasiones en que se hace referencia a su vínculo. Es una mujer muy menuda, ansiosa, que está notoriamente molesta por tener que acceder a este encuentro y que desde el comienzo manifiesta que ella no cree que el problema sea Pedro sino los com- 
pañeros y en especial el colegio que no logra manejar esta situación. Cuando se le pregunta, ¿Cuál situación? Ella responde: "como verá, y señala a su compañera, yo soy lesbiana y esto que hoy le digo así me llevó mucho tiempo aceptarlo. Viví diez años con el padre de Pedro y cada vez que se acercaba a mi me daba pavor.... un pavor solamente comparable al que sentía cuando de niña mi padre me pegaba y manoseaba. Yo creía que era por eso y entonces me convencía de que él no era mi padre y de que si yo podía establecer algo bueno con él seguramente todo eso borraría mi pánico...que no era solamente en la cama... yo tenía pavor todo el día y mucho más cuando estaba con él..." Mas adelante expresa "lo bueno de todo eso es que vino Pedro, al que hoy adoro, es el sentido de mi vida, el sí que me quitó todos los miedos... porque cuando nació imagínese... varón...y yo con esos antecedentes...por eso decidí dejar todo y obligarme a estar con él así podíamos los dos perder ese miedo esencial y así lo hice, y así salió y ahora que él está bien y yo también, y podemos disfrutar de esta vida real que nos armamos me vienen con todo esto". Cuando se le señala su actitud de molestia con la consulta ella aclara..."bueno, ahora que veo que me escucha, que no me está diciendo lo que está bien y lo que está mal, no tendría problemas...si ud lo puede ayudar a que no le pase lo que a mi, a que se acepte, a que sea feliz siendo como es, a que no necesite disfrazarse de varón para dejar contento al mundo, todo va a andar bien....que no le pase como al padre y a mi que perdimos tantos años y recién ahora somos felices.... ¿ud va a ir a hablar al colegio?" Así formulaban estos padres su demanda: que ayudara al niño a aceptar lo que ellos veían como una clara orientación homosexual.

\section{Pedro}

Pedro es un niño gordito, simpático, que rápidamente se presta al encuentro manteniéndose permanentemente muy atento a mi.

Quiero compartir con uds partes del material de los primeros encuentros a partir de los cuales buscaríamos comprender que era lo que le pasaba a Pedro, como él lo sentía, y cómo lo podríamos ayudar.

A pocos minutos de entrar al consultorio se dirige a la caja de juegos, saca la vaca y me la entrega: "esta tenela tu..." luego saca el elefante, un tigre pequeño, un corderito y allí ve al toro y hace un gesto como de rechazo y me dice "Ios toros son malos...este es malo... hacen así contra el suelo y tiran a la gente, vamos a ponerlo acá" (y lo pone sobre una silla alejada de la mesa de trabajo). Sigue sacando más animales hasta que da un pequeño grito cuando ve a la víbora, se retira hacia atrás protegiéndose con las manos..."esta es una lombriz y los pica (a los otros animales)... ahora viene el elefante y mata a la lombriz mala y queda la lombriz buena y el canguro le dice al corderito..jugá nomás que es la buena..."

Más adelante manifiesta que él quisiera ser como el cangurito que está en la panza de la mamá y que "no quisiera nunca ser como el elefante que es tan grande.... pero yo me parezco a la serpiente (ya no la llama lombriz), porque hay serpientes grandes y otras chiquitas y esta es chiquita como este hueso de mi pierna (y señala el femur) que tiene como una piolita para que no se caiga..." En un segundo encuentro comienza haciendo este dibujo al que él llama "el bebé montaña", porque "quise hacer una montaña, grande, pero me salió este bebé envuelto (se rie)... como los niños envueltos que se comen".

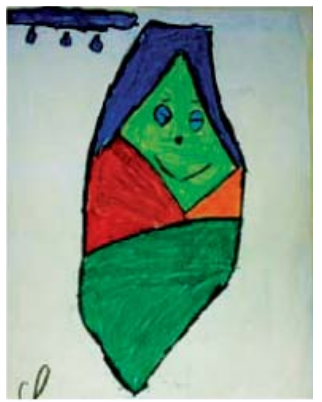

En otra entrevista realiza este dibujo de una familia dónde él se identifica con la primera figura y al finalizar mientras me contaba cómo era esta familia escribe "NADIE"

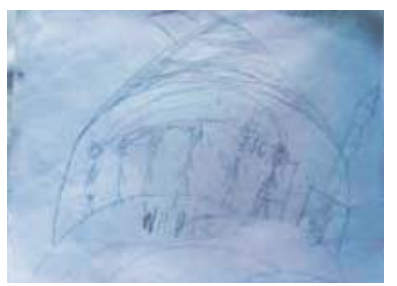

Frente a la consigna de dibujar "una persona bajo la lluvia" realiza lo siguiente:

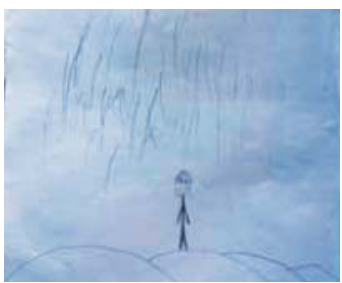




\section{Formulación de caso Pedro}

Pedro, de 6.8 años de edad, es derivado a la consulta por comportamientos amanerados que causaban la burla de sus compañeros y le llevaban a respuestas violentas, a una irritabilidad general y a conductas propias de un niño menor. Proviene de un núcleo familiar claramente disfuncional. Sus padres se separaron cuando el tenia tres años por infidelidad de la esposa con una persona de su mismo sexo. El padre se siente sumamente afectado por esta situación que le remite a un sentimiento de fracaso y desvalorización de la cual busca desembarazarse. La madre por su lado, víctima de un abuso infantil, desea transformar a Pedro en un varón al que ella no le tema: un varón que no tenga conductas masculinas. Frente a esta situación el niño, que evidencia muy buenas herramientas cognitivas, busca complacerlos a ambos para lograr de esa manera un lugar seguro y una valoración positiva. Evidencia entonces actitudes femeninas, temor a lo masculino y fundamentalmente una muy fuerte dependencia que nos muestra que el niño se siente sumamente exigido, apresado en estos deseos parentales, sin convicción alguna de poder satisfacer esas exigencias tanto internas como externas y con una enorme necesidad de cuidado y protección. La escasa dependencia primaria no favorece la autonomía y atenta contra una imagen de sí mismo consistente y esto lo mantiene temeroso. Se defiende de este desvalimiento que se hace evidente con sus pares, a través de actitudes agresivas con las que busca imponerse. Oscila entonces entre la pasividad (frente a padres y adultos en general) y la agresividad (frente a sus pares). Sus defensas se tornan rígidas y empobrecen su capacidad de adaptación y aprendizaje.

Pedro no ha logrado el nivel de integración de su identidad correspondiente a su nivel de desarrollo. Su apego inseguro, su capacidad reflexiva empobrecida, dan cuenta de un nivel pobre de mentalización. El niño teme a sus impulsos a los que no puede controlar. Evidencia en consecuencia limitaciones moderadas en su funcionamiento mental, funcionando en un nivel neurótico en el que la conflictiva está centrada en la constitución de su identidad.

Demuestra cierta conciencia de sus dificultades y pide ayuda para enfrentarlas. Esto, unido a sus herramientas cognitivas, a su capacidad para la expresión afectiva y para el relacionamiento en la medida en que se siente valorado y sostenido, nos llevan a indicar una intervención que comenzará por un trabajo con sus padres en el que se buscará trabajar con ellos su incidencia en la sintomatología de Pedro así como sus expectativas con respecto al niño específicamente en relación a la identidad sexual de cada uno de ellos. Por otro lado se trabajará con Pedro fortaleciendo e integrando sus representaciones de sí en aras de ayudarle a conformar una identidad genuina y acorde a sus deseos y condiciones.

\section{Consideraciones finales}

Luego de expuestos los casos y presentadas las formulaciones clínicas pudimos comprobar la importancia de contextualizar la evaluación del niño tanto en el nivel de desarrollo esperado así como en el contexto que lo rodea. Es a partir de estos parámetros que haremos una evaluación de las herramientas cognitivas, afectivas y de relacionamiento, que caracterizan su emergente organización de personalidad, en base a lo cual daremos cuenta de la entidad de los síntomas, del impacto que estos puedan estar generando en el proceso de crecimiento así como de sus posibilidades de adaptación y pronóstico. Recién entonces definiremos la necesidad y/o posibilidades de intervención.

\section{Referencias}

Altman, M. (compiladora), 2014. "Time for Change: Tracking Transformations in Psychoanalysis The ThreeLevel Model". Karnac Books, London.

Dio Bleichmar, Emilce. (2005) Manual de psicoterapia de la relación padres e hijos. Bs. As. Paidós.

Klein, M. (1962) La técnica psicoanalítica del juego. Nuevas direcciones en psicoanálisis. Bs. As. Paidós.

Miller, D. (2013). "Las Huellas del afecto. Estudio de la incidencia de la regulación afectiva en el desarrollo de la personalidad". Ed.Magro. Montevideo.

PDM. (2006). Psychodynamic Diagnostic Manual. Silver Spring: Alliance of Psychoanalytic Organizations.

Winnicott, D. (1982) Realidad y juego. Barcelona: Gedisa. 


\section{APÉNDICE}

\section{PREGUNTAS GUIA PARA LA FORMULACIÓN CLÍNICA DE CASO EN NIÑOS}

\section{EXPERIENCIA SUBJETIVA DE LA ENFERMEDAD}

a. ¿cuáles son los principales problemas y síntomas del paciente? ¿Cuál es la experiencia subjetiva que el niño tiene de los mismos? ¿Cuáles son sus creencias acerca de lo que le ocurre y sus expectativas acerca del tratamiento? ¿En qué medida el paciente reconoce sus problemas como tales? ¿Cuál es la perspectiva de los padres sobre los problemas del niño? ¿Cuál es la perspectiva de los maestros? ¿Hasta dónde vislumbra el niño los caminos que podrían llevar a un cambio? ¿Y los padres? ¿Hasta dónde analista, paciente y padres (podrían corresponder también otros informantes) concuerdan sobre las transformaciones esperadas?

b. ¿Existen factores contextuales que afectan especialmente al sujeto? (e.g., situaciones de crisis, experiencias traumáticas, enfermedades somáticos, etc.) ¿Cuán capaz es el paciente de hacer frente a estas situaciones?

\section{PATRONES DE RELACIONAMIENTO INTERPERSONAL}

a. Patrones relacionales generales: ¿Cómo son las relaciones interpersonales del paciente, especialmente en los vínculos que implican cercanía e intimidad? ¿Tienen profundidad, amplitud y consistencia? ¿Cómo experimenta el niño a los otros? ¿Cómo se experimenta a sí mismo en relación con los otros? (e.g., ¿El niño se siente cómodo y relajado en presencia del adulto? ¿Es amistoso, evitativo o busca atención excesivamente? ¿Cómo es su contacto visual, verbal y corporal?) ¿Cómo experimentan los otros (madre, padre, hermanos, pares) al niño y a sí mismos en relación al niño? ¿Cómo es su relacionamiento con ellos?

b. Patrones relacionales con el terapeuta: Qué característica presenta la relación transferencial contratransferencial?(e.g., ¿Cómo es el relacionamiento con el terapeuta, es cómodo y relajado? ¿Muestra dudas al principio para conectarse? ¿Su juego es aislado, solitario en el análisis? ¿Sus vínculos, en el juego son de reciprocidad, de cooperación? ¿de competencia? ¿Hay inhibición?) ¿Logra vincularse de una manera próxima e íntima? ¿Puede expresarse este relacionamiento a través de las palabras?

\section{PRINCIPALES CONFLICTOS INTRAPSÍQUICOS:}

a. ¿Cuáles son los principales conflictos y los afectos relacionados a ellos? (e.g., individuación, autoestima, culpa, conflicto edípico, conflicto de identidad, ...). ¿Cuáles son las fantasías inconscientes dominantes que pueden inferirse de los conflictos?

b. ¿Tiene el padre/madre las capacidades para calmar y proporcionar medidas adecuadas para la contención y enfrentamiento del conflicto? ¿Tiene el padre/madre capacidades para regular la ansiedad, para el reconocimiento, la tolerancia y apaciguamiento, ayudando a codificar como pasibles de resolución los conflictos con la realidad interna y externa?

c. ¿Las defensas son adecuadas y flexibles o predominantemente disfuncionales, distorsionando o restringiendo las experiencias internas y externas?

d. ¿Qué afectos acompañan esta dinámica? (e.g., ¿Manifiesta agresividad? ¿Cautela? ¿Miedo? ¿Placer? ¿Alegría?, ¿Reacciones de frustración? ¿Enojo? ¿Rabia? ¿Sorpresa? ¿Zozobra? ¿Tristeza? ¿Pérdida? ¿Puede controlarse? ¿Está preocupado por los efectos de la misma sobre los otros?)

4. FUNCIONAMIENTO MENTAL O DE PERSONALIDAD. ESTRUCTURA: ¿Cuál es el nivel de funcionamiento mental del niño en las siguientes áreas?

I. Percepción de sí mismo y de los otros. Identidad.

¿Cuán capaz es el niño, tomando en cuenta el nivel de desarrollo esperado de percibir adecuadamente sus propios estados internos y los de los demás? ¿Es capaz de empatía, tolerando y comprendiendo diferentes puntos de vista? ¿Tiene un sentido integrado de su propia identidad y correspondiente al nivel de desarrollo esperado? ¿Puede integrar en su identidad su propio pasado y en especial las experiencias traumáticas de la forma que sería esperable considerando su nivel de desarrollo? ¿Cuáles son las características de las identificaciones dominantes?

¿Cómo es su percepción y representación de sí mismo? (integrada-contradictoria, adecuada-inadecuada, distónica-sintónica).

¿Cómo son sus estados afectivos al respecto? ¿Siente desprecio, aprecio, vergüenza, orgullo de sí mismo? ¿Cómo son sus representaciones objetales? (e.g., habilitadoras, persecutorias, idealizadas, desvalorizadas, frágiles...)

¿Cómo son sus manifestaciones en relación a la dependencia y autonomía esperadas para su nivel de desarrollo? (e.g., se muestra voluntarioso y quiere hacer las cosas por sí mismo; insiste en que las cosas se hagan como quiere; se enoja si no es así, se enoja si no logra lo que quiere).

¿Actúa libremente de acuerdo a sus deseos, a sus deberes? ¿Actúa reactivamente? (e.g., presenta manifestaciones de oposicionismo,) ¿Muestra flexibilidad o terquedad y obstinación? 
¿El niño muestra placer en sus éxitos solamente si le muestran aprobación?

\section{Regulacion sensorial}

Tomando en cuenta el nivel esperado para su desarrollo

¿Cómo es su habilidad para controlar el grado, intensidad, y naturaleza de sus respuestas a los estímulos sensoriales? (e.g., ¿Respuesta excesiva con miedo, ansiedad, negativismo, terquedad, ensimismamiento?) ¿Cómo reacciona a los diferentes estímulos (sonidos, luces, tacto)? (Ej: falta de respuesta, respuesta excesiva, etc.)

Integración psique-soma: ¿Cómo vive su cuerpo? ¿Siente que le gusta? ¿Hay signos en su postura corporal que llamen la atención? ¿En su forma de caminar?¿Tiene el niño enfermedades orgánicas? ¿se enferma frecuentemente? ¿Cuáles son sus manifestaciones y vivencias sobre las mismas? ¿Cómo son las vivencias de los padres sobre la enfermedad? ¿Esta incidencia de factores somáticos han sido reveladores de alguna situación? Si es así, ¿ha podido descubrir en el análisis los factores que preceden su desorganización psique-soma, por ejemplo apatía, depresión, retraimiento? ¿Cuán fuerte es la influencia de factores dependientes del contexto (e.g., cambios vinculados al desarrollo, enfermedades somáticas, medicación, estresores agudos o crónicos, situaciones traumáticas, etc.) y cuán capaz es el paciente de hacer frente a esas dificultades? ¿Tiene el padre/madre las capacidades para proveer un sentimiento de vitalidad y entusiasmo? ¿Tiene el padre/madre capacidad para la regulación de los estados fisiológicos (sueño, hambre, activación, sedación, dolor, temperatura. ¿En qué medida los padres logran comprender lo que le pasa al niño y tener una respuesta que lo ayude?

¿Cuál es su nivel general de actividad? ¿Cuánto varía este nivel de actividad? ¿Tiene capacidad para mantener el foco de su atención en una actividad o interacción? ¿Qué tiempo promedio se le dedica a un juguete o actividad determinada? ¿Se distrae con frecuencia? ¿Cómo inciden los padres en estos aspectos?

\section{Regulación afectiva}

Comenzaremos por hacernos ciertas preguntas generales que nos orientarán respecto al desarrollo de la capacidad para la regulación afectiva:

¿Qué estilo de apego y capacidad reflexiva evidencia el niño? ¿y sus padres? ¿Qué modelo de regulación le fue sugerido o aprobado? (e.g., consideramos los siguientes aspectos: ¿Tiene el padre/madre las capacidades como adultos para la ternura, para la erogeneidad inhibida en su fin? ¿Tiene el padre/madre las capacidades para tomar en consideración las razones que hay detrás de las acciones de los demás? ¿Tiene el padre/madre las capacidades para tomar en cuenta los sentimientos, estados mentales y deseos de su hijo? ¿Tiene el padre/madre las capacidades para anticipar el peligro y el desamparo? ¿Tiene el padre/madre las capacidades para la regulación de la ansiedad, angustia, de su hijo? ¿ Tiene el padre/madre las capacidades para la construcción de un vínculo de apego seguro y tolerancia tanto a la dependencia temprana como a la creciente autonomía? ¿Tiene el padre/madre las capacidades para contribuir a la regulación psíquica de su hijo? ¿Tiene el padre/madre las capacidades para disminuir su angustia? El padre/madre responde inmediatamente a las necesidades de su hijo? (De seguridad física, de vínculo afectivo, de erogeneidad) ¿Tiene el padre/madre las capacidades para contrarrestar sus angustias de fragmentación?

En función de lo anterior definiremos:

¿Como siente el niño en sí mismo y percibe en los otros la amplia gama de afectos esperables a su edad? ¿Hasta dónde logra procesar sus impulsos y experiencias emocionales de manera que favorezcan su adaptación y satisfacción?

¿Lo ayudan sus normas e ideales a reconocer y tolerar sus experiencias emocionales ante las adversidades, manteniendo una estabilidad acorde a su nivel de desarrollo emocional?

¿Puede regular su autoestima frente a las exigencias internas y externas? ¿Tiene la capacidad de equilibrar los intereses propios y ajenos protegiéndose y protegiendo sus vínculos?

¿Es capaz de regular las relaciones con los otros (capacidad de intimidad, de reciprocidad y de cuidado de sí y del otro en las relaciones)?

¿En qué medida el niño puede integrar sentimientos positivos y negativos hacia sì mismo y hacia los demás? ¿Cómo lo ubicaría con respecto al nivel de desarrollo esperado para la edad? ¿Y con respecto al modelo recibido desde la familia?

\section{Comunicación interna y externa y simbolización.}

¿Cuán rico es el diálogo consigo mismo y con los demás, basado en experiencias afectivas, fantasías, sueños, sexualidad, self corporal y representaciones simbólicas? ¿Cómo lo ubicaría con respecto al nivel de desarrollo esperado para la edad?

¿Cuenta con las herramientas necesarias y las ha desarrollado de forma adecuada? (e.g, ¿Es su vocalización y producción del discurso adecuada para su edad? ¿Comprende bien el discurso del otro? ¿El proceso de pensamiento primario y/o de sus verbalizaciones en el juego es esperable para su grupo etario? ¿Cómo usa la información para la resolución de problemas?)

¿Tiene el padre/madre las capacidades para ayudar en este proceso? 


\section{Vínculos con objetos internos y externos.}

¿Cuán profundas y estables son las relaciones con objetos internos y externos? ¿Hasta dónde puede crear relaciones de intimidad y reciprocidad basadas en representaciones estables y diferenciadas de sí mismo y de los otros? ¿Cómo maneja las relaciones que implican la existencia de un tercero?

¿Cuán capaz es el niño de iniciar y terminar relaciones y afrontar separaciones?

¿Cómo lo ubicaría con respecto al nivel de desarrollo esperado para la edad?

\section{FOCOS TERAPÉUTICOS:}

¿Cuáles son los aspectos que han sido especialmente atendidos por el terapeuta en sus intervenciones y que puede suponerse, que para el terapeuta juegan un papel central psicodinámico en el cuadro clínico, originando o manteniendo los conflictos? ¿Hasta dónde terapeuta, niño, cuidadores y maestros coinciden en la necesidad de trabajar en torno a ellos?

\section{NIVEL Y TIPO DE TRASTORNO}

1) ¿Es posible identificar un tipo de trastorno de desarrollo, de personalidad u otro tipo de trastorno?

2) ¿El nivel de la organización de la personalidad se orienta hacia un funcionamiento saludable, neurótico o fronterizo? ¿Pudo centrarse el trabajo terapéutico en conflictos neuróticos o fue necesario atender antes o al mismo tiempo a fallas estructurales en el funcionamiento y la integración psíquica que afectaban la estabilidad de los conflictos y del trabajo terapéutico?

Para citar esta Comunicación:

Miller, D. (2015). Formulación psicodinámica de caso en niños. Ciencias Psicológicas 9(2): 203 - 215 